\title{
Combination between Taxol-Encapsulated Liposomes and Eruca sativa Seed Extract Suppresses Mammary Tumors in Female Rats Induced by 7,12 Dimethylbenz( $\alpha$ )anthracene
}

\author{
Nadia Shaban ${ }^{1}$, Salah Abdel-Rahman²*, Amany Haggag², Doaa Awad ${ }^{1}$, Ahmad \\ Bassiouny $^{1}$, Iman Talaat ${ }^{3}$
}

\begin{abstract}
Taxol (paclitaxel) is a powerful anti-cancer drug widely used against several types of malignant tumors. Because Taxol may exert several side effects, a variety of formulations have been developed. One of these features liposomes, regarded as one of the most promising drug carriers, biocompatible and best able to reduce drug toxicity without changing efficacy against tumor cells. Eruca sativa seed extract (SE) is considered a promising natural product from cruciferous vegetables against breast cancer, increasing chemotherapeutic and eliminating harmful side effects. The effects of Taxol-encapsulated liposomes ( $T$ ) alone and in combination between Eruca sativa seed extract on nuclear factor kappa B (NF- $\varkappa$ B), cyclooxygenase-2 (COX-2) and B-cell lymphoma-2 (Bcl-2) gene expression levels were investigated in rat mammary gland carcinogenesis induced by 7,12 dimethylbenz $(\alpha)$ anthracene (DMBA) using qRT-PCR. The results showed that DMBA increased NF- $x \mathrm{~B}, \mathrm{COX}-2$ and Bcl-2 gene expression levels and lipid peroxidation (LP), while decreasing glutathione-S-transferase (GST) and superoxide dismutase (SOD) activities and total antioxidant concentration (TAC) compared to the control group. $T$ and T-SE treatment reduced NF- $\varkappa$ B , COX-2 and Bcl-2 gene expression levels and LP. Hence, T and T-SE treatment appeared to reduce inflammation and cell proliferation, while increasing apoptosis, GST and SOD activities and TAC.
\end{abstract}

Keywords: DMB A - breast cancer - Taxol-encapsulated liposomes - Eruca sativa - NF-kB - bcl-2 - COX-2 - qRT-PCR

Asian Pac J Cancer Prev, 17 (1), 117-123

\section{Introduction}

Breast cancer is the second most common cancer in the world. The most common types of breast cancer are ductal and lobular carcinoma (Zeeneldin et al., 2013). 7, 12 dimethylbenz( $\alpha)$ anthracene (DMBA) is an immunosuppressor and a powerful organ-specific laboratory carcinogen, it serves as a tumor initiator (Saha and Hait, 2012). Paclitaxel (Taxol) is an effective anticancer agent against variety of human tumors such as non-small cell lung cancer (NSCLC), ovarian cancer, breast cancer, head and neck cancer and melanoma (Rowinsky et al., 1990). Because of the low water solubility and the high inflammatory response, the extensive clinical usage of Taxol is limited. Thus, much effort has been made in eliminating the side effects during administration. A variety of formulations have been developed, one of those is liposome which regards one of the most promising drugs carrier. Where, liposome is biocompatible and able to reduce drug toxicity without changing drug efficacy against tumor cells (Kan et al., 2011). Eruca sativa (Rocket plant) is a member of the Brassica plant family which known that is an alternative treatment for treating and preventing cancer. Like other cruciferous vegetables, the preliminary phytochemical studies of rocket seeds revealed the presence of carotenoids, flavonoids, phenolics, vitamins and glucosinolates which metabolized into isothiocyanates (Melchini and Traka, 2010). Nuclear factor kappa $\mathrm{B}(\mathrm{NF}-\varkappa \mathrm{B})$ is a nuclear transcription factor that regulates the expression of various genes, such as B-cell lymphoma-2 (Bcl-2) and cyclooxygenase-2 (COX-2), that involved in cell proliferation, adhesion, angiogenesis, apoptosis, cytoprotection, carcinoge $\neg$ nesis, and inflammation. The activation and regulation of the expression of these gene products leading to cell cycle arrest, suppression of proliferation and induction of apoptosis (Escarcega et al., 2007). Apoptosis represents a physiological process for removing damaged or infected cells and maintaining tissue homeostasis (Shaban et al., 2013). During tumorigenesis, cancer cells develop the ability to avoid apoptosis through the upregulation of antiapoptotic proteins and/or downregulation of proapoptotic signalling pathways. Bcl-2 family of both pro- and antiapoptotic proteins are central regulators of apoptosis 
(Yip and Reed, 2008). COX-2 is an inducible enzyme, stimulated by cytokines, growth factors, oncogenes or tumour promoters during inflammation or malignancy. Overexpression of COX-2 has been detected in a number of tumors, such as breast, lung, pancreatic and colorectal cancers (Sobolewski et al., 2010). The current study is to investigate the therapeutic effect of the combination between Taxol-encapsulated liposome and Eruca Sativa seed extract against DMBA-induced mammary gland carcinogenesis through the study of gene expression of $\mathrm{NF}-x \mathrm{~B}, \mathrm{COX}-2$ and $\mathrm{Bcl}-2$, as well as lipid peroxidation and antioxidant parameters. In addition, histopathological examination of breast and profile tests of liver and kidney were determined.

\section{Materials and Methods}

\section{Eruca sativa seeds extract (SE) preparation}

Three kilograms of Eruca sativa seeds obtained from a market (Alexandria, Egypt) were grained. Grained seeds were soaked in $95 \%$ ethanol in an incubator shaker (150 $\mathrm{rpm}$ ) at $30^{\circ} \mathrm{C}$ for two days (Harborne, 1988). The extract was concentrated to dryness using rotary evaporator (Heidolph) to yield dried ethanolic extract, which was $12.89 \%(\sim 386.7 \mathrm{~g})$ of the starting material. Then the ethanolic extract was converted to powder using lypholizer (TELSTAR, Cryodos), which was 11\% ( 330 g) of the starting material. It should be noted that Eruca sativa seeds extract (SE) was characterized in our previous study (Abdel-Rahman et al., 2015).

\section{Preparation of liposomes/Taxol complex}

Taxol (Paclitaxel) was added to the alcoholic mixture of Distearoylphosphatidylcholine (DSPC), Cholesterol, and Distearoylphosphatidylethanolamine-polyethylene glycol (DSPE - PEG2000), with a given drug-to-lipid molar ratio (Kan et al., 2011). The solution was evaporated under vacuum in rotary evaporator to remove the solvent and formed a lipid film on the wall of the round-bottom flask at which time; $4 \mathrm{ml}$ of phosphate buffer saline were added to the flask for hydration. Liposomes were suspended, and then vortex for 15 minutes to yield Large multilamellar liposomes. The liposomes were sealed in the vial under nitrogen and stored at $4^{\circ} \mathrm{C}$ for further shelf stability.

\section{Experimental animal model}

Twenty-eight female Sprague-Dawley rats (weighing about 80-100 g at age 40 days) were obtained from Misr University for Science and Technology, Cairo, Egypt. Rats were examined for health status, housed and handled under ethical conditions according to the international rules of animal care. Rats were divided into four groups (seven rats/group). Experimental animal design was as follows: Control (C) group (administered orally with corn oil), DMBA (D) group (administered with DMBA dissolved in corn oil, $20 \mathrm{mg} / 100 \mathrm{~g}$ body weight) (Carroll et al., 2010), DMBA and Taxol encapsulated liposome (T) group (administered with DMBA as group D and then the rats were treated with intravenous taxol encapsulated liposome (20mg/kg body weight/week for four weeks) (Kan et al.,
2011) and DMBA, Taxol encapsulated liposome and SE (T-SE) group (administered with DMBA as group $\mathrm{D}$ and then the rats were treated orally with SE (500 $\mathrm{mg} / \mathrm{kg}$ body weight /day for four weeks) (Behrens and Karber, 1970) and also injected with intravenous taxol encapsulated liposome $(20 \mathrm{mg} / \mathrm{kg}$ body weight/week for four weeks) (Kan et al., 2011). Rats were palpated every day for mammary tumors. The cumulative number of tumor masses was calculated by each day's palpation of rats. Tumor volume (v) was determined by the following equation: $\mathrm{V}=(\mathrm{L} \times \mathrm{W} 2) / 2$, where $\mathrm{L}$ is the length and $\mathrm{W}$ is the width of the tumor. During treatment, animals were observed daily for signs of morbidity and mortality. Body masses were recorded initially, once weekly and at the end of the experimental period. At the end of the experimental period, feeding was stopped $12 \mathrm{~h}$ before dissection, then the rats were sacrificed and the mammary tissues of each animal were dissected and immediately put in RNA later and kept at $-80^{\circ} \mathrm{C}$ for the molecular study analysis.

\section{Quantitative real time polymerase chain reaction ( $q R T$ - PCR)}

From mammary gland rat's tissue, total RNA was isolated using Gene JET RNA Purification Kit (Thermo Scientific, USA). The extracted RNAs from different samples were quantified and qualified (purity) using NanoDrop Spectrophotometer. Finally, total RNAs samples were normalized (same concentration) to avoid any false increase in gene expression levels. Using SYBER Green 1-step qRT-PCR Kit (Thermo Scientific, USA), gene expression of BCl-2, NF-kB and COX-2 (target genes) and $\beta$-actin (reference gene) were quantified by Real-Time PCR System (Thermo Scientific PikoReal) with the use of specific primers sequences (Forward/ Reverse) 5'-GGTGCCACCTGTGGTCCACCTG-3'/5' CTTCACTTGTGGCCCAGATAGG-3' for BCl-2 gene (Saleha, 2010), 5' -CTGGCAGCTCTTCTCAAAGC-3'/5'CCAGGTCATAGAGAGGCTCAA-3' for NF-kB gene (Yar et al., 2011), 5'-CTGTATCCCGCCCTGCTGGTG3'/5 ' - T TGCGT T GATGG TGGCTGTCT T-3' for COX-2 gene (Rani and Kansal, 2011) and 5' - GTGGGCCGCTCTAGGCACCAA-3'/5 ' CTCTTTGATGTCACGCACGATTTC-3' for $\beta$-actin gene (Todorova et al., 2006; Saleha, 2010). qRT-PCR was performed in a reaction mixture of $10 \mu \mathrm{l}$ using $0.1 \mu \mathrm{l}$ verso enzyme mix, $5 \mu$ l 1-step QPCR SYBER mix (1X), $0.5 \mu \mathrm{l}$ RT-enhancer, $0.5 \mu \mathrm{l}$ forward and reverse primers (10 pm), 0-2.9 $\mu \mathrm{l}$ water (PCR grade) and 0.5-3.4 $\mu \mathrm{l} \mathrm{RNA}$ template (50 ng). qRT-PCR program was applied as one cycle of cDNA synthesis at $50^{\circ} \mathrm{C}$ for $15 \mathrm{~min}$, one cycle of Thermo-start enzyme activation at $95^{\circ} \mathrm{C}$ for $15 \mathrm{~min}$ and followed by 40 cycles of denaturation at $95^{\circ} \mathrm{C}$ for 15 sec, annealing at $60^{\circ} \mathrm{C}$ for $1 \mathrm{~min}$ and extension at $72^{\circ} \mathrm{C}$ for $30 \mathrm{sec}$.

\section{Antioxidant and oxidative stress profiles}

One gram of the mammary gland tissue was homogenized in 5 volumes of cold $0.1 \mathrm{M}$ sodium phosphate buffer saline (PBS), pH 7.4 using Teflon glass homogenizer at $4^{\circ} \mathrm{C}$. The total homogenate was centrifuged using cooling centrifuge at about $7000 \mathrm{rpm}$ for 
$20 \min$ at $4^{\circ} \mathrm{C}$. The supernatant $(\mathrm{MH})$ was stored at $-20^{\circ} \mathrm{C}$ until used for the determination of malondialdhyde (MDA) level, superoxide dismutase (SOD) and glutathioneS-transferase (GST) activities (Nishikimi et al., 1972; Habig et al., 1974; Ohkawa et al., 1979). Moreover, total antioxidant concentration (TAC) was determined colorimetrically in serum (Nishikimi et al., 1972).

\section{Liver and kidney profile tests}

Alanine aminotransferase (ALT) activity, albumin, protein, urea and creatinine levels were determined in serum (Gornall et al., 1949; Reitman and Frankel, 1957; Doumas et al., 1971).

\section{Histopathological studies}

Mammary tissues were fixed in $10 \%$ formalin for 24 hour, washed with running water, dehydrated in ascending grades of alcohol $(70 \%, 80 \%, 95 \%$ and absolute alcohol) and cleaned by immersion in xylene followed by impregnation in melted paraffin wax in oven at $60^{\circ} \mathrm{C}$ for $1 \mathrm{hr}$. The specimens were embedded in paraffin and were left to solidify at room temperature. Using a rotary microtone, sections of $5 \mu \mathrm{m}$ thick were cut and were mounted on clean glass slides. Finally, the samples were stained with conventional hematoxylin and eosin (H\&E) stain for examination under light microscope for any histopathological changes.

\section{Statistical analysis}

Statistical analyses were performed using the statistical software, SPSS (Version 13). Results were presented as means $(\mathrm{X}) \pm$ standard deviation $(\mathrm{SD})$.

\section{Results}

\section{Tumor incidence and its volume}

Tumor incidence was significantly increased by $100 \%$ at day 120 after DMBA injection (Figure 1A). Also, the tumor volume in DMBA (D) group was significantly increased by $100 \%$ compared to the control group (C). The results showed that the treatment with $\mathrm{T}$ and T-SE after DMBA decreased the tumor volume significantly by $96.9 \%$ and $99.1 \%$, respectively compared to the D group (Figure 1B).

\section{Body masses of rats}

Body masses of the rats at the day 120 (100\% tumor appearance) were decreased significantly by about $18.4 \%$, $14.5 \%$ and $11.2 \%$ in D, T and T-SE groups, respectively (Figure 1C). At the day 160 (after treatment by T and SE), body masses were decreased significantly by about $19 \%$ in D group compared to the $\mathrm{C}$ group. On the other hand, body masses were increased significantly by about $11 \%$ and $10 \%$ in $\mathrm{T}$ and T-SE groups, respectively compared to the $\mathrm{D}$ group.

\section{Gene expression of $\mathrm{NF}-\mathrm{kB}, \mathrm{Bcl}-2$ and $\mathrm{COX}-2$}

The expression levels of NF-kB, Bcl-2 and COX-2 genes in $\mathrm{D}$ group were significantly increased by about $341 \%, 261 \%$ and $603 \%$, respectively compared to the $\mathrm{C}$ group. While, the expression level in $\mathrm{T}$ group was significantly decreased by about $84 \%, 95 \%$ and $99.5 \%$, respectively compared to the $\mathrm{D}$ group. The expression level of NF-KB, Bcl-2 and COX-2 genes in T-SE group was significantly decreased by about $98 \%, 81 \%$ and $99.6 \%$, respectively compared to the D group (Figure 2A, B and C).

\section{Antioxidant and oxidative stress profiles}

SOD activity was significantly decreased in D group by about $66 \%$ compared to the $\mathrm{C}$ group, while, in $\mathrm{T}$ and T-SE groups was significantly increased by about $154 \%$ and $303 \%$, respectively compared to the D group (Figure 3A). GST activity was significantly decreased in D group by about $42 \%$ compared to the $\mathrm{C}$ group, while,
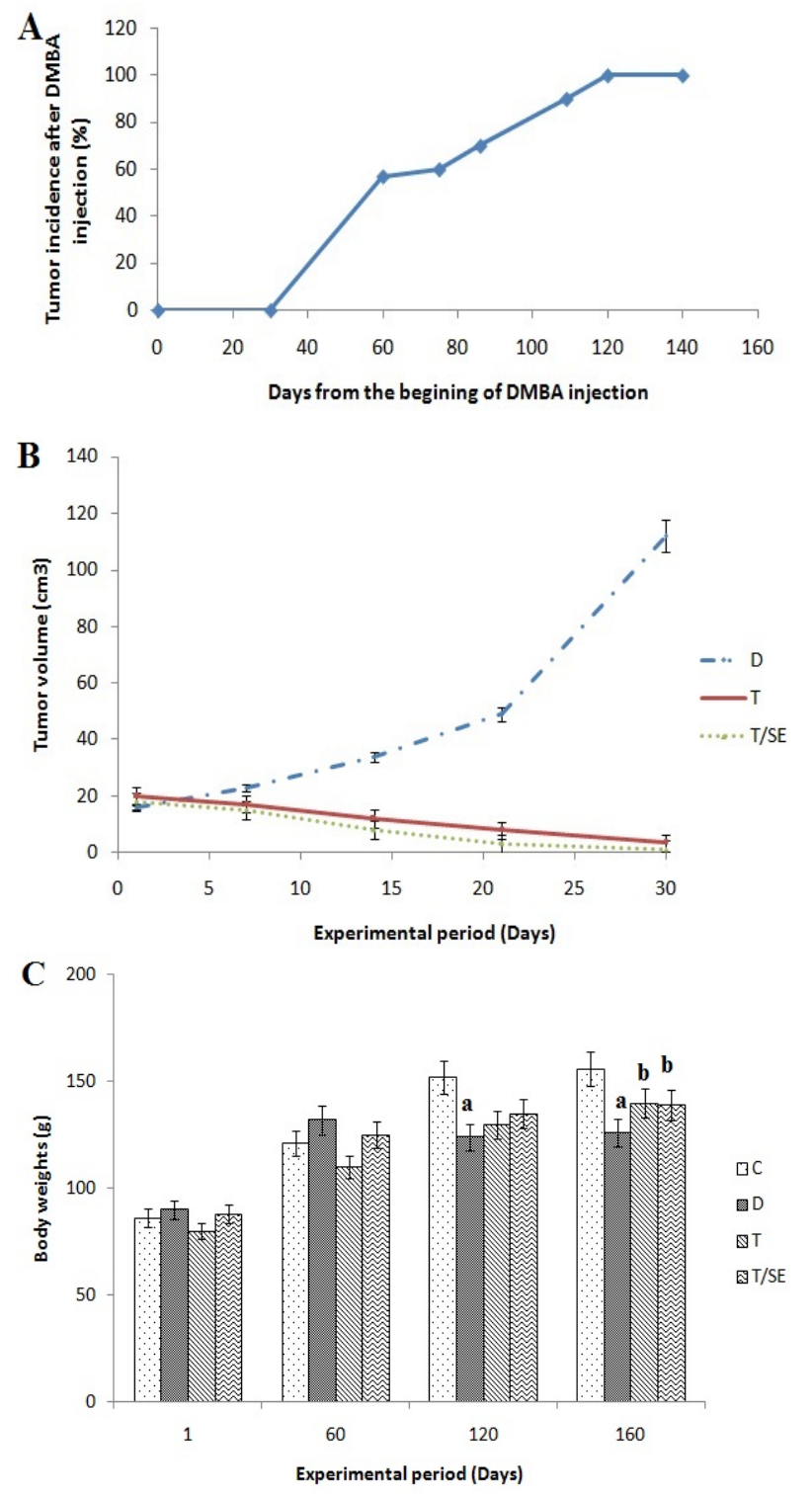

Figure 1. Tumor Incidence, Volume and Body Masses of Studied Groups. (A). Tumor incidence of rats during the experimental period (B). Tumor volume of rats during the experimental period (C). Body masses of rats during the experimental period. Where, a: significant with the $\mathrm{C}$ group, $\mathrm{b}$ : significant with the $\mathrm{D}$ group, at $\mathrm{p}<0.05$. Group C: Control group; group D: rats injected with DMBA; group T: rats injected with DMBA and then treated with T; group T-SE: rats injected with DMBA and then treated with $\mathrm{T}$ and SE 


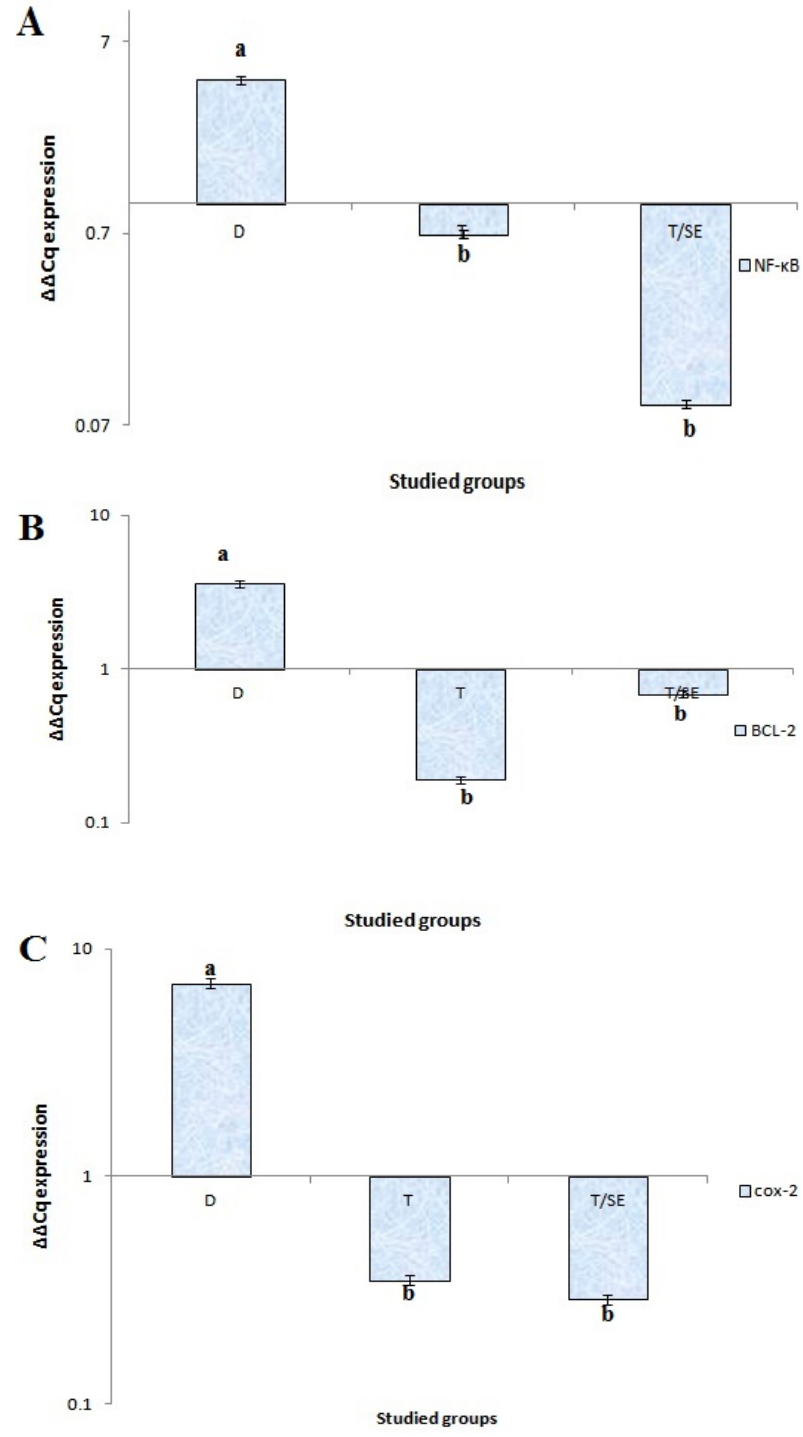

Figure 2. Genes Expression of Nf- $\varkappa b$, Bcl-2 and COX2 of Studied Groups. (A). Gene Expression level of Nf- $x \mathrm{~b}$ during the experimental period (B). Gene Expression level of Bcl-2 during the experimental period (C). Gene Expression level of COX-2 during the experimental period. Where, a: significant with $\mathrm{C}$ group, b: significant with $\mathrm{D}$ group, at $\mathrm{p}<0.05$. Group $\mathrm{C}$ : Control group; group D: rats injected with DMBA; group T: rats injected with DMBA and then treated with T; group T-SE: rats injected with DMBA and then treated with $\mathrm{T}$ and SE

in $\mathrm{T}$ group showed a non significant change compared to the D group. In T-SE group increased significantly by about $239 \%$ compared to the D group (Figure 3B). TAC was significantly decreased in D group by about $37 \%$ compared to the $\mathrm{C}$ group, while, in $\mathrm{T}$ and T-SE groups was significantly increased by about $207 \%$ and $209 \%$, respectively compared to the D group (Figure $3 \mathrm{C}$ ). The level of MDA of D group was significantly increased by about $275 \%$ compared to the $C$ group, while, in $\mathrm{T}$ and T-SE groups were significantly decreased by about $27 \%$ and $40 \%$, respectively compared to the D group (Figure 3D).

\section{Liver and kidney profile functions}

Albumin and protein levels were significantly decreased in D group compared to the $\mathrm{C}$ group, while, in $\mathrm{T}$ and T-SE group were significantly increased compared

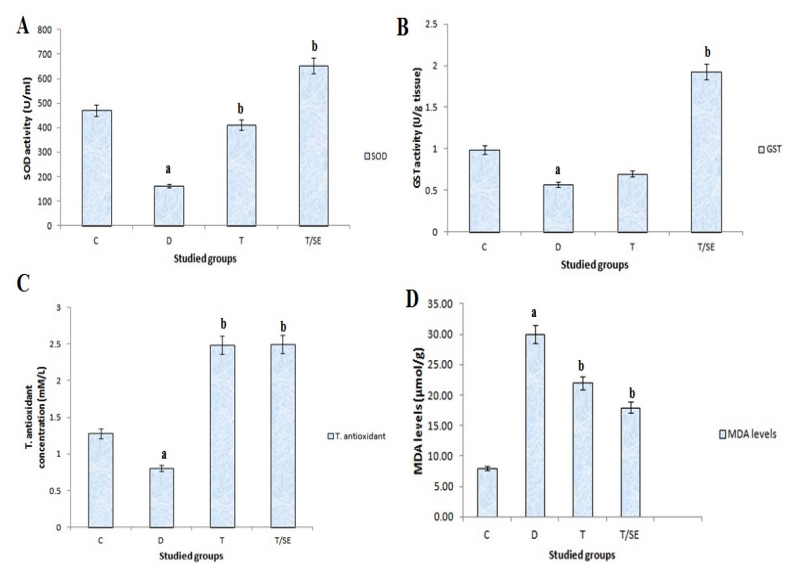

Figure 3. Alterations in the Levels of Lipid Peroxidation and Antioxidants of Studied Groups. (A) SOD activity (B) GST activity (C) Total antioxidant concentration (D) MDA levels. Where, a: significant with $\mathrm{C}$ group, b: significant with $\mathrm{D}$ group, at $\mathrm{p}<0.05$. Group C: Control group; group D: rats injected with DMBA; group T: rats injected with DMBA and then treated with T; group T-SE: : rats injected with DMBA and then treated with $\mathrm{T}$ and $\mathrm{SE}$

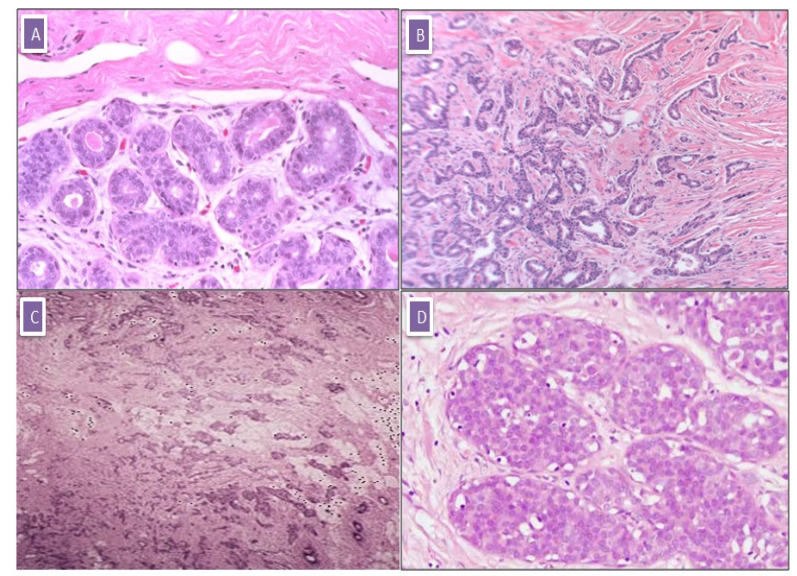

Figure 4. Histological Examination of Mammary

Gland Tissue of Studied Groups. (A) C group (H\&E, x400) Examination of this group showed a dense collagenous tissue, blood vessels and islands of glandular tissue surrounded by dense fibrous and adipose tissue. The breast acini and tubules are lined by inner epithelial layer (with dense cytoplasm) and outer myoepithelial layer (with clearer cytoplasm) (B) D group (H\&E, $\mathrm{x} 200$ ): Administration of rats with DMBA revealed a neoplastic growth made up of trabeculae, ducts, and nests of malignant ductal cells having rounded to ovoid vesicular nuclei with prominent nucleoli and indistinct cell borders. The cytoplasm is abundant and eosinophilic. Mitotic figures are discerned. The stroma is desmoplastic and infiltrated by lymphocytic infiltrate mainly lymphocytes. Areas of necrosis are identified as well as foci of carcinoma in situ, whether the comedo form or the solid form. Foci of dystrophic calcification are noted in some sections (C) T group (H\&E, x100): In addition examination of mammary gland tissues of rats which treated with $\mathrm{T}$ after DMBA administration revealed no infiltrating component by the malignant cells. Areas of necrosis are noted as well as foci of carcinoma in situ. The stroma is infiltrated by lymphocytes. Cellular debris is discerned (D) T-SE group (H\&E, x100): rats which treated with both $\mathrm{T}$ and SE after DMBA administration revealed foci of carcinoma in situ whether comedo subtype or solid subtype. No infiltrating component seen. Hyalinization of the stroma as well as infiltration by lymphocytes is observed. Pyknosis of the cells is identified 
Taxol-encapsulated Liposomes and Eruca sativa Seed Extract Suppress Mammary Tumors in Female Rats Table 1. Liver and Kidney Profile Functions

\begin{tabular}{|c|c|c|c|c|}
\hline \multirow[t]{2}{*}{ Test } & \multicolumn{4}{|c|}{ Studied groups } \\
\hline & $\mathrm{C}$ & $\mathrm{D}$ & $\mathrm{T}$ & T-SE \\
\hline Albumin (g/dl) & $3.87 \pm 0.51$ & $2.40 \pm 0.36 \mathrm{a}$ & $3.39 \pm 0.22 b$ & $3.10 \pm 0.005 b$ \\
\hline$\%$ change from $\mathrm{C}$ & 0 & -38 & -12 & -20 \\
\hline$\%$ change from $\mathrm{D}$ & -- & 0 & 41 & 29 \\
\hline Total protein (g/dl) & $6.95 \pm 1.31$ & $5.45 \pm 0.27 \mathrm{a}$ & $6.05 \pm 0.21 b$ & $6.35 \pm 0.00 b$ \\
\hline$\%$ change from $\mathrm{C}$ & 0 & -21 & -13 & -9 \\
\hline$\%$ change from $\mathrm{D}$ & -- & 0 & 11 & 17 \\
\hline ALT (U/ml) & $30 \pm 1.91$ & $34 \pm 5.45$ & $32 \pm 5.23$ & $29 \pm 0.00$ \\
\hline$\%$ change from $\mathrm{C}$ & 0 & 13 & 7 & -3 \\
\hline$\%$ change from $\mathrm{D}$ & -- & 0 & -6 & -9 \\
\hline Creatinine (mg/dl) & $0.69 \pm 0.39$ & $0.91 \pm 0.02 \mathrm{a}$ & $0.83 \pm 0.07 b$ & $0.70 \pm 0.00 b$ \\
\hline$\%$ change from $\mathrm{C}$ & 0 & 32 & 20 & 1.4 \\
\hline$\%$ change from D & -- & 0 & -9 & -23 \\
\hline Urea $(\mathrm{mg} / \mathrm{dl})$ & $26 \pm 5.5$ & $48 \pm 3.3 \mathrm{a}$ & $29 \pm 1.2 b$ & $30 \pm 0.00 b$ \\
\hline$\%$ change from $\mathrm{C}$ & 0 & 87 & 11 & 16 \\
\hline$\%$ change from $\mathrm{D}$ & -- & 0 & -41 & -36 \\
\hline
\end{tabular}

*Values are expressed as mean \pm S.D. for six rats. Where, a: significant with C group, b: significant with $\mathrm{D}$ group, at $\mathrm{p}<0.05$. The positive values in the $\%$ change mean there was an increase and the negative values mean there was a decrease. Group C: Control group; group D: rats injected with DMBA; group T: rats injected with DMBA and then treated with T; group D-SE: rats injected with DMBA and then treated with T and SE. ALT: Alanine aminotransferase

to D group. ALT activity was nonsignificantly changed compared to $\mathrm{C}$ and $\mathrm{D}$ groups. Creatinine and urea levels in D group were significantly increased compared to C group, while, in $\mathrm{T}$ and T-SE group were significantly decreased compared to D group (Table 1).

\section{Histological examination of mammary gland tissues}

Examination of the $\mathrm{C}$ group showed a dense collagenous tissue, blood vessels and islands of glandular tissue surrounded by dense fibrous and adipose tissue. The breast acini and tubules are lined by inner epithelial layer with dense cytoplasm and outer myoepithelial layer with clearer cytoplasm (Figure 4A). Administration of rats with DMBA (D group) revealed a neoplastic growth made up of trabeculae, ducts, and nests of malignant ductal cells having rounded to ovoid vesicular nuclei with prominent nucleoli and indistinct cell borders. The cytoplasm was abundant and eosinophilic. Mitotic figures were discerned. The stroma was desmoplastic and infiltrated by lymphocytic infiltrate mainly lymphocytes. Areas of necrosis were identified as well as foci of carcinoma in situ, whether the comedo form or the solid form. Foci of dystrophic calcification were noted in some sections (Figure 4B). In addition, examination of mammary gland tissues of rats which treated with $\mathrm{T}$ after DMBA administration showed no infiltrating component by the malignant cells. Areas of necrosis are noted as well as foci of carcinoma in situ. The stroma is infiltrated by lymphocytes. Cellular debris is discerned (Figure 4C). Also, examination of mammary gland tissues of rats which treated with T-SE after DMBA showed foci of carcinoma in situ whether comedo subtype or solid subtype. No infiltrating component seen. Hyalinization of the stroma as well as infiltration by lymphocytes is observed. Pyknosis of the cells is identified (Figure 4D).

\section{Discussion}

In this study, tumors incidence and their volumes were significantly increased after DMBA administration in rats. These results were in line with histopathological, biochemical and molecular results which revealed the carcinogenic effect of DMBA. These may be due to the binding of dihydrodiol epoxide (an active metabolite of DMBA) with adenine or guanine residues of DNA forming a stable DMBA-DNA adducts. These adducts induce proto-oncogenes or inactivate tumor suppressor genes as an important event during tumor initiation and carcinogenesis (Abdel-Rahman et al., 2015). The histopathological examination of rats treated with Taxol encapsulated liposome (T) and Taxol encapsulated liposome with SE (T-SE) after DMBA administration were in line with the biochemical and molecular results of this study. The results showed that MDA level and the gene expression of NF- $x \mathrm{~B}, \mathrm{COX}-2$ and $\mathrm{BCL}-2$ were decreased compared to the rats administered with DMBA only (D group), conversely, GST, SOD activities and TAC were significantly increased. That's mean, the anti-neoplastic chemotherapy effect may be due to the generation of oxidative stress and induction of the apoptosis in tumor cells (McLean et al., 2008). Oxidative stress can activate proto-oncogenes and increase the NF$\varkappa \mathrm{B}$ and AP-1transcription factors as well as it can inhibit the apoptosis through the modulation of Myc, Bcl-2 and p53 expression (Klaunig et al., 1998; Rossi et al., 2009). The inhibitory effects of T may be related to the liposomal paclitaxel formulation which improves its solubility and efficacy. In vivo tissue uptake of paclitaxel was evaluated after intravenous injection of Taxol PEGylated liposome in breast carcinoma xenografted mouse model. In tumor tissue, paclitaxel concentration in PEGylated liposomes was significantly higher than that in Taxol at 6 and $24 \mathrm{~h}$ (Yang et al., 2007). PEGylated liposomes were distinctly localized in the tumor tissues as it seemed that longcirculating time and slow release of PEGylated liposomes might offer enough chance for paclitaxel to be attained at the tumor site and maintain the effective therapeutic concentration for a long period of time. Therefore, 
PEGylated liposomal formulation effectively increased the antitumor efficiency and decreased the potential sideeffects. It has been reported that the PEGylated liposomes suppressed breast cancer tumor growth most efficiently compared to Taxol alone. This enhanced anti-tumor activity of the PEGylated liposomes can be explained by the increased local concentration of paclitaxel near the tumor via the enhanced permeability and retention (EPR) effect (Sarah and David, 2012). The elevation of total protein and albumin concentrations in rats treated with $\mathrm{T}$ and T-SE after DMBA administration indicates that $\mathrm{T}$ had an important role in the improvement of liver cells. Since, $\mathrm{T}$ increase protein synthesis in damaged liver and improve the functional statues of the liver cells. Therefore, reduction on ALT activity was noticed in rats treated with T after DMBA administration. The reduction of creatinine and urea concentrations in rats treated with $\mathrm{T}$ after DMBA administration indicates that $\mathrm{T}$ had a protective effect against nephrotoxicity of DMBA. However, the promising inhibitory effects of T-SE may be related to the effect of both SE and taxol encapsulated liposome. Where, liposomal taxol formulation improves taxol solubility and efficacy, while, SE contains high yields of total phenolics, flavonoids, alkaloids, triterpenoids, antioxidant capacity, anti-lipid peroxidation, reducing power and DPPH radical scavenging effect as mentioned in our previous study (Abdel-Rahman et al., 2015). Also, SE acts as antioxidant, anti-inflammatory and anticancer by reducing oxidative stress, lipid peroxidation, inflammation and cell proliferation in breast tissues which were induced by DMBA and its metabolites.This is due to SE enhanced the detoxification of DMBA through induction of phase II drug metabolizing enzymes, reduction of carcinogen activation through suppression of cytochrome P450-dependent monooxygenases, promotion of apoptosis in cancer cells, perturbation in cell cycle progression and inhibition of angiogenesis and metastasis (Melchini and Traka, 2010). SE can prevent the process of carcinogenesis by multiple mechanisms perturbing the three major steps initiation, promotion and progression, as well as, the later stages, angiogenesis and metastasis. The mechanisms of action include modulation of phase I, II and III detoxification, regulation of cell growth by induction of apoptosis with cell cycle arrest, induction of ROS-mechanisms and regulation of androgen receptor pathways (Melchini and Traka, 2010). However, SE considers a promising natural product from cruciferous vegetables against breast cancer in combination with Taxol encapsulated liposome, which, increase its chemotherapeutic effect and eliminate its harmful side effects. Also, liposome formulation acts as a drug delivery system for efficient delivery to tumor cells and to eliminate the drug side effects.

\section{References}

Abdel-Rahman S, Shaban N, Haggag A, et al (2015). Inhibition of NF-kB, bcl-2 and COX-2 genes expression by Eruca Sativa seeds extract in rat mammary gland carcinogenesis. Asian Pac J Cancer Prev, 16, 8411-18.

Behrens B, Karber G (1970). Chemotherapy of Neoplastic Diseases Selli C, Ckhardt S and Nmeth L (eds.). Budapest,
The publishing House of the Hungarian Academy, 37.

Carroll CE, Benakanakere I, Besch-Williford C, et al (2010). Curcumin delays development of medroxyprogesterone acetate-accelerated 7,12-dimethylbenz[a]anthraceneinduced mammary tumors. Menopause, 17, 178-84.

Doumas BT, Watson WA, Biggs HG (1971). Albumin standards and measurement of serum albumin with bromcresol green. Clin Chim Acta, 31, 87-96.

Escarcega RO, Fuentes-Alexandro S, Garcia-Carrasco M, et al (2007). The transcription factor nuclear factor-kappa B and cancer. Clin Oncol, 19, 154-61.

Gornall AG, Bardawill CJ, David MM (1949). Determination of serum proteins by means of the biuret reaction. J Biol Chem, 177, 751-66.

Habig WH, Pabst MJ, Jakoby WB (1974). Glutathione $\mathrm{S}$-transferases. The first enzymatic step in mercapturic acid formation. J Biol Chem, 249, 7130-9.

Harborne JB (ed.) (1988). Phytochemicals Methods, Chapman and hall, London.

Kan P, Tsao CW, Wang AJ, et al (2011). A liposomal formulation able to incorporate a high content of Paclitaxel and exert promising anticancer effect. J Drug Deliv, 2011, 629234.

Klaunig JE, Xu Y, Isenberg JS, et al (1998). The role of oxidative stress in chemical carcinogenesis. Environ Health Perspect, 106, 289-95.

McLean L, Soto U, Agama K, et al (2008). Aminoflavone induces oxidative DNA damage and reactive oxidative species-mediated apoptosis in breast cancer cells. Int $J$ Cancer, 122, 1665-74.

Melchini A, Traka MH (2010). Biological profile of erucin: a new promising anticancer agent from cruciferous vegetables. Toxins, 2, 593-612.

Nishikimi M, Appaji N, Yagi K (1972). The occurrence of superoxide anion in the reaction of reduced phenazine methosulfate and molecular oxygen. Biochem Biophys Res Commun, 46, 849-54.

Ohkawa H, Ohishi N, Yagi K (1979). Assay for lipid peroxides in animal tissues by thiobarbituric acid reaction. Anal Biochem, 95, 351-8.

Rani R, Kansal VK (2011). Study on cow ghee versus soybean oil on 7,12-dimethylbenz(a)-anthracene induced mammary carcinogenesis \& expression of cyclooxygenase-2 \& peroxisome proliferators activated receptor-gamma in rats. Indian J Med Res, 133, 497-503.

Reitman S, Frankel S (1957). A colorimetric method for the determination of serum glutamic oxalacetic and glutamic pyruvic transaminases. Am J Clin Pathol, 28, 56-63.

Rossi T, Panis C, Victorino V, et al (2009). Breast cancer and oxidative stress in chemotherapy. Applied Cancer Res, 29, 150-6.

Rowinsky E, Cazenave L, Donehower R (1990). Taxol: a novel investigational antimicrotubule agent. J Natl Cancer Inst, 82, $1247-59$

Saha D, Hait M (2012). An ontological design: two stage mouse skin carcinogenesis induced by dmba and promoted by croton oil. Asian J Res Pharm Sci, 2, 01-3.

Saleha YM (2010). Gene expression and histopathology alterations during rat mammary carcinogenesis induced by 7,12-dimethylbenz[a]anthracene and the protective role of Neem (Azadirachta indica) leaf extract. J Am Sci, 6.

Sarah B, David RK (2012). The treatment of breast cancer using liposome technology. J Drug Delivery, 2012.

Shaban NZ, El-Kersh MA, El-Rashidy FH, et al (2013). Protective role of Punica granatum (pomegranate) peel and seed oil extracts on diethylnitrosamine and phenobarbitalinduced hepatic injury in male rats. Food Chem, 141, 1587-96. 
Taxol-encapsulated Liposomes and Eruca sativa Seed Extract Suppress Mammary Tumors in Female Rats

Sobolewski C, Cerella C, Dicato M, et al (2010). The role of cyclooxygenase- 2 in cell proliferation and cell death in human malignancies. Int J Cell Biol, 2010.

Todorova VK, Kaufmann Y, Luo S, et al (2006). Modulation of p53 and c-myc in DMBA-induced mammary tumors by oral glutamine. Nutr Cancer, 54, 263-73.

Yang T, Cui FD, Choi MK, et al (2007). Enhanced solubility and stability of PEGylated liposomal paclitaxel: In vitro and in vivo evaluation. Int $J$ Pharmaceut, 338, 317-26.

Yar AS, Menevse S, Alp E (2011). The effects of resveratrol on cyclooxygenase-1 and -2, nuclear factor kappa beta, matrix metalloproteinase- 9 , and sirtuin 1 mRNA expression in hearts of streptozotocin-induced diabetic rats. Genetics Molecular Res, GMR, 10, 2962-75.

Yip KW, Reed JC (2008). Bcl-2 family proteins and cancer. Oncogene, 27, 6398-406.

Zeeneldin AA, Ramadan M, Gaber AA, et al (2013). Clinicopathological features of breast carcinoma in elderly Egyptian patients: A comparison with the non-elderly using population-based data. J Egyptian National Cancer Institute, 25, 5-11. 